J O U R N A L

$\mathrm{O} F \bullet \mathrm{B} A \mathrm{~L} T$ I C

$S$ C I E N C E

EDUCATION

ISSN 1648-3898 /Print/
ISSN 2538-7138/Onine/

Abstract. The use of animated concept mapping (ACM) has been linked to an innovative learning skill when conducting students' guidance of 4 corresponding reasoning processes in electrochemistry. This research aims to establish a new perspective with ACM cognitive reasoning to broaden students' individual developments of problem-solving skills. It is followed by a quasi-experimental approach of pre-tests, post-tests and retention-tests designed for 274 qualified college students in Taiwan. All data collected from students' learning performances and feedback is further analyzed by means of achievement covariance,

t-tests and one-way ANOVA. Analytical results reveal that $A C M$ facilitates learning comparisons and out-performances in two

groups of students in different post-test and retention-test scores. Students' positive

feedback and learning disposition also provide the predominant advantage for participants' successful reasoning processes. Pedagogical implications suggest that ACM learning performances result in more

significant collaborative reasoning.

Key words: animated concept mapping, corresponding reasoning processes, electrochemistry learning performances, problem-solving

King-Dow Su Hungkuo Delin University of Technology, Taiwan

Chung Yuan Christian University, Taiwan

\author{
ENHANCING STUDENTS' \\ CDRRESPロNDING \\ REASDNING DF CDGNITIVE \\ PERFDRMANCES BY ANIMATED \\ CDNCEPT MAPPING IN \\ ELECTRDCHEMISTRY
}

\section{King-Dow Su}

\section{Introduction}

Few academic studies are as concerned with students' creative performances in cognitive reasoning processes as animated concept mapping (ACM) has been in the past two decades. With the goal of evaluating a nodelink between the cognitive reaction and interaction, ACM is an effective teaching aid and useful learning tool suitable for different levels of science students. Because it is a challenging diagnostic tool, ACM provides a method for constructing conceptual knowledge which will reduce cognitive overloading in students while learning science (Novak, 2010; Te'eni, Carey, \& Zhang, 2007). In order to justify more favorable future, ACM can give guidance for students to construct conceptual understanding of scientific knowledge and to amass problem-solving skills in chemistry learning (Hwang, Wu, \& Ke, 2011; Simons \& Klein, 2007). Moreover, as labeled models of constructive nodes and lines, ACM learning tool can also be designed for students' immediate response of composite concepts and integrated animations. During the acquired processes of informative reasoning, visual changes will be evoked sequentially in a diagram or chart of complicated or abstract systems (Adesope \& Nesbit, 2013).

In subsequent research, several instructors have proposed features to incorporate visual animations into concept mapping in a scientific approach for students to enact more creative meta-analyses with conceptual reasoning (Nesbit \& Adesope, 2006). For example, scholars demonstrated that students could amass the aid of multimedia animations combined with multidimensional concept maps to promote their cognitive instructions (Chiou, Tien, \& Lee, 2015). Additionally, many multimedia animations consisting of words, moving pictures, sounds and images, can improve students' ability to understand complex concepts, and identify misconceptions. This is attributable to an increase in learners' motivation, satisfaction, instructional efficiency and comprehensive understanding (Holzinger, Kickmeier-Rust, \& Albert, 2008; Lin \& Atkinson, 2011). To be a preparatory and effective tool, concept mapping 
could be used as a learning strategy in collaborative reasoning for assessing conceptual knowledge acquisition, (Soika \& Reiska, 2014) and for enhancing students' spoken narration (Adesope et al., 2013). Suitable for objective grouping learning, many scholars advocate that the above visual animations and incorporated narration can be embedded in technology-based environments as a means to enhance learning in science education (Weinerth, Koenig, Brunner, \& Martin, 2014).

As a consequence, it is evident that the integrated concept mapping and visual animations are helpful to students in the learning of electrochemistry. The results show that the new technology proposed in this research significantly enhances students' learning performances of four corresponding problem-solving reasoning processes in the following way: (1) model-based reasoning focuses on models with different variables; (2) case-based reasoning aims at student classifications or two group of students; (3) rule-based reasoning refers to cognitive patterns derived from mental models and (4) symbol-based reasoning suggests an application of the recognizable symbol in students' manipulating decision (Kraft, Strickland, \& Bhattacharyya, 2010; Christian \& Talanquer, 2012). These four corresponding reasoning processes provide a concise means of problem-solving based on how innovative technology is stored and organized during their development of decision-making.

There are many advantages for researchers to combine concept mapping and visual animations. For instance, concept mapping provides a potential means to an end of meaningful guidance for those students who struggle to learn scientific knowledge and are unable to detect their own shortcomings of problem-solving performances (David, 2003; Kao, Lin, \& Sun, 2008). Specifically, the application of concept mapping would guide students in building their learning efficiency for scientific knowledge (Hwang et al., 2011; Liu, Lin, \& Tsai, 2009; Novak, 2010). Another illustration of innovative technologies is visual animations which combine words, movies, diagrams, and sounds in chemistry instruction to attract students' attention, stimulate their motivations to learn, and create an effective integrated learning environment (Su, 2008). As a high-order example of abstract or complicated reasoning, electrochemistry learning should not be confined to only one application of concept mapping or visual animations. Students are often puzzled by their own misconception of individual reasoning in conceptual learning (Akram, Johari \& Ali, 2014; Cheung, 2011).

This research is a new project to incorporate both concept mapping and visual animations in students' four corresponding problem-solving reasoning processes. Within students' individual and collaborative learning, the concept mapping of ACM sets up their critical thinking in scientific organization, classification, analysis, evaluation and reasoning processes. In recent research, teaching strategic applications of ACM has received more and more attention from science instructors to improve students' problem-solving abilities (Chiou et al., 2015; Huang et al., 2012). Accordingly, this research proposes four basic reasoning models of ACM learning cognitive skills for assessing students' problem-solving abilities in the context of electrochemistry learning.

\section{Problem Statement}

The purpose of this research is twofold: (1) discovering what potential performance improvements can be hidden in students' four corresponding reasoning processes (2) constructing students' individual developments of ACM learning associated with their understanding of electrochemistry concepts. Based on these two-fold purpose, three fundamental problem-solving are directed into three orientations: (i) to compare two group students' posttests and retention-tests; (ii) to confirm significant improvements of students' ACM problem-solving skills; and (iii) to elucidate experimental group students' target feedback. The better students get a complete command of the four ACM cognitive reasoning process, their higher individual developments of problem-solving skills render an accumulated and continuous transposition of collaborative learning in electrochemistry.

\section{Research Focus}

The implementation of this research follows students' participation in a strategic application of ACM learning cognitive skills. It takes on an innovative learning with the four corresponding reasoning for active involvement of concept mapping and visual animations in electrochemistry. The target concepts are derived from the following construction for conceptual reasoning and algorithmic proficiency through problem-solving skills in learning achievement. As shown in Table 1, students will combine target concepts and their problem-solving skills into 
their reasoning flow charts of electrochemistry to increase their target concepts, conceptual understanding and algorithmic proficiency.

Table 1. Target concepts and problem-solving skills of concept flow charts.

\begin{tabular}{|c|c|}
\hline Target concept & Problem-solving skills of concept flow charts \\
\hline - To determine mass of a substance & $\begin{array}{l}\text { Particle numbers }(N) \rightarrow \text { Avogadro's number }(N A) \rightarrow \text { mole number }(n) \rightarrow \text { Molar mass }(M) \rightarrow \\
\operatorname{mass}(m) n=(N / N A) ; m=n \times M\end{array}$ \\
\hline - Mass percent composition & $\begin{array}{l}\text { Mass of a constituent element }(\mathrm{m}) \rightarrow \text { Molar mass of a compound }(\mathrm{M}) \rightarrow \text { Mass fraction }(\mathrm{Xi}) \rightarrow \\
\text { Mass percent }(\mathrm{P}) \mathrm{Xi}=\mathrm{m} / \mathrm{M} ; \mathrm{P}=\mathrm{Xi} \times 100 \%\end{array}$ \\
\hline $\begin{array}{l}\text { - To determine empirical formulas stoichiometric } \\
\text { reaction }\end{array}$ & $\begin{array}{l}\text { Percent of elements } \rightarrow \text { mass } \rightarrow \text { mole numbers } \rightarrow \text { the smallest integers ratio } \rightarrow \text { molecular } \\
\text { formulas and empirical formula } \rightarrow \text { molecular mass } \rightarrow \text { molecular formula }\end{array}$ \\
\hline - Stoichiometric equivalence and & $\begin{array}{l}\text { Balance chemistry equations } \rightarrow \text { find out stoichiometric equivalent } \rightarrow \text { stoichiometric factors } \\
\text { (mole ratios) }\end{array}$ \\
\hline - Yields of chemical reactions & $\begin{array}{l}\text { To identify limiting reactant } \rightarrow \text { stoichiometric proportions of reactants } \rightarrow \text { to calculate quantity } 0 \\
\text { products } \rightarrow \text { theoretical yields }\end{array}$ \\
\hline
\end{tabular}

\section{Methodology of Research}

\section{General Background}

The background of model-based reasoning focuses on four different variables, they are: control variables, independent variables, dependent variables, and covariate variables. These combine to create an integrated ACM environmental learning framework, and are illustrated in the following points:

(1) Control variables: Its function is to reduce interference and obtain authentic ACM experimental results. The assessment of control variables in this study is minimized by employing the same instructor, the same content, the same teaching hours, and the same evaluation tools. (2) Independent variables: Specific statistical findings are given for variables in students' personal data (dispositions toward electrochemistry) and group divisions (i.e., ACM experimental group and static texts (ST) control group) in relation to instructors' teaching strategy. (3) Dependent variables: Students are required to write, discuss and hand in their experimental reports after classes. The instructor administers achievement tests to evaluate two groups of students. Another variable is to the use the questionnaire to survey learning attitudes and students' interviews after achievement tests. (4) Covariate variables: The instructor will carry out students' achievement pre-tests as the major covariance before their electrochemistry schedule program in 2015.

\section{Sample Participants}

In order to identify case-based reasoning validity and reliability, all participants were selected and postulated through two stages of qualification tests. At the first stage of qualification tests, 218 participants aged 18-21 years, were chosen from undergraduate students to take author' the electrochemistry course. For the first stage candidates, it was conducted a pilot test to gather validity and reliability of learning achievements and attitude in accordance with these qualified participants. Up to the second stage of qualification tests, another 56 participants were qualified to postulate for the normal pilot participation of the scores from $B$ to $A^{-}$with the same pre-knowledge. To avoid the Hawthorne effect, 56 participants were randomly assigned to two groups evenly for a quasi-experimental approach, namely the ST control group, and the ACM experimental group. All 274 undergraduate participants were volunteers with full understanding that the results would not be anonymous and the results may be published. Ethical approval was obtained for this research (Taber, 2014) in 2015. The core research texts for the ACM group were augmented with the strategic visual animations to integrate into concept mapping. In contrast, the ST group was taught with traditional text methods of static teaching without any assistance of strategic applications. All texts used in this research were examined and validated by three chemistry professors. 


\section{Instruments and Procedures}

The procedures for this research were organized in five categories, they are: pre-tests, ACM learning texts, posttests, retention-tests and structural and semi-structural questionnaires in the required electrochemistry assessments for university students. With a new learning perspective to enhance students' engagement of electrochemistry, Table 2 outlines the two groups' research procedures for electrochemistry.

Learning achievement is estimated through students' participation in pre-tests, post-tests and retention-tests by identifying their best electrochemistry skills and uncovering conceptual and algorithmic problem-solving abilities. Pilot test items were collected to meet the targeted Bloom's six levels (Anderson \& Krathwohl, 2001) with the revised resources from Cheung (2011). The content of the 12 achievement tests was validated by three chemistry and science education professors.

With respect to pilot test items in the learning achievement tests, the mean difficulty index was .45 , the mean discrimination index was .41 , and reliabilities of the Cronbach's a were .85 . The results of the pilot test indicated perceived difficulty and good discrimination, as well as higher reliability of test item scores (Salta \&Tzougraki, 2004).

A Learning attitude questionnaire was designed to improve the experimental group's ACM learning feedback. The students were rated based on a 5-point Likert scale to the test items in the author's draft design (Su, $2008,2016)$ and revisions. Two science philosophers and one educational psychologist served as advisors to check the questionnaire design for content validity. From the 180 effective copies (82.6\%) of pilot tests, we derived two stages of constructive validity. Table 3 outlines the first stage with significant Kaiser-Meyer-Olkin (KMO) and the second stage with six Eigenvalue (E), accumulative explanation variation (AEV) and Cronbach's a value to show internal consistency inspection. According to Gay's research theory (Gay, 1992), this questionnaire had higher reliability than others.

Table 2. Research procedures for the two student groups in the Electrochemistry course.

\begin{tabular}{cccccc}
\hline Group & Pre-test & Treatment & Post-test & Retention-test & Questionnaire \\
\hline ACM & V & E & $V$ & $V$ & V \\
ST & V & C & V & V & \\
\hline
\end{tabular}

Note: The word $\mathrm{V}$ indicates testing; E denoted experimental group with ACM texts; C represented control group with static texts.

Table 3. Two stages of constructive validity for learning attitude questionnaire.

\begin{tabular}{ll}
\hline Stage & \multicolumn{1}{c}{ Investigate data } \\
\hline The first stage & $\mathrm{KMO}=.919, \chi 2=3317.481, \mathrm{p}<.05$ \\
The second stage & $\mathrm{E}>1.0, \mathrm{AEV}=63.219 \%, \alpha=.948$ \\
\hline
\end{tabular}

The six Eigenvalue could be recognized as the following six subscales: $A_{1}$, Students'

learning attitude with $A C M$ learning texts; $A_{2}$, Students' learning attitude with $A C M$ learning development and presentation texts; $A_{3^{\prime}}$ Students' learning attitude with affection toward teachers; $A_{4^{\prime}}$, Students' learning attitude with ACM learning environment; $A_{5}$, Students' learning attitude with active ACM learning engagement; and $A_{6}$, Students' learning attitude with ACM text learning results. In accordance with the above structural questionnaire, this study offered semi-structural analysis to obtain a framework of authentic opinions and critical thinking in the students' deficiency of learning feedback.

ACM learning texts improved students' accretion of problem-solving abilities, with special instructions on the self-design learning texts from the ACM student group. The ST group followed traditional chemistry learning texts without any strategic application assistance. Students' cumulative theoretical knowledge combined well with their ACM practical skills and applications in the electrochemistry learning environment. Their ACM learning texts indicated an increased integration of individual conceptual approach and animation-based visual activities toward the ACM group. One of the benefits of ACM learning texts in this research includes a concise organization of concept mapping and three integrated visual animations with cognitive narration. Figure 1 illustrates that students' screen perception of a static concept mapping explains the connections between visualized knowledge and organized concepts. 


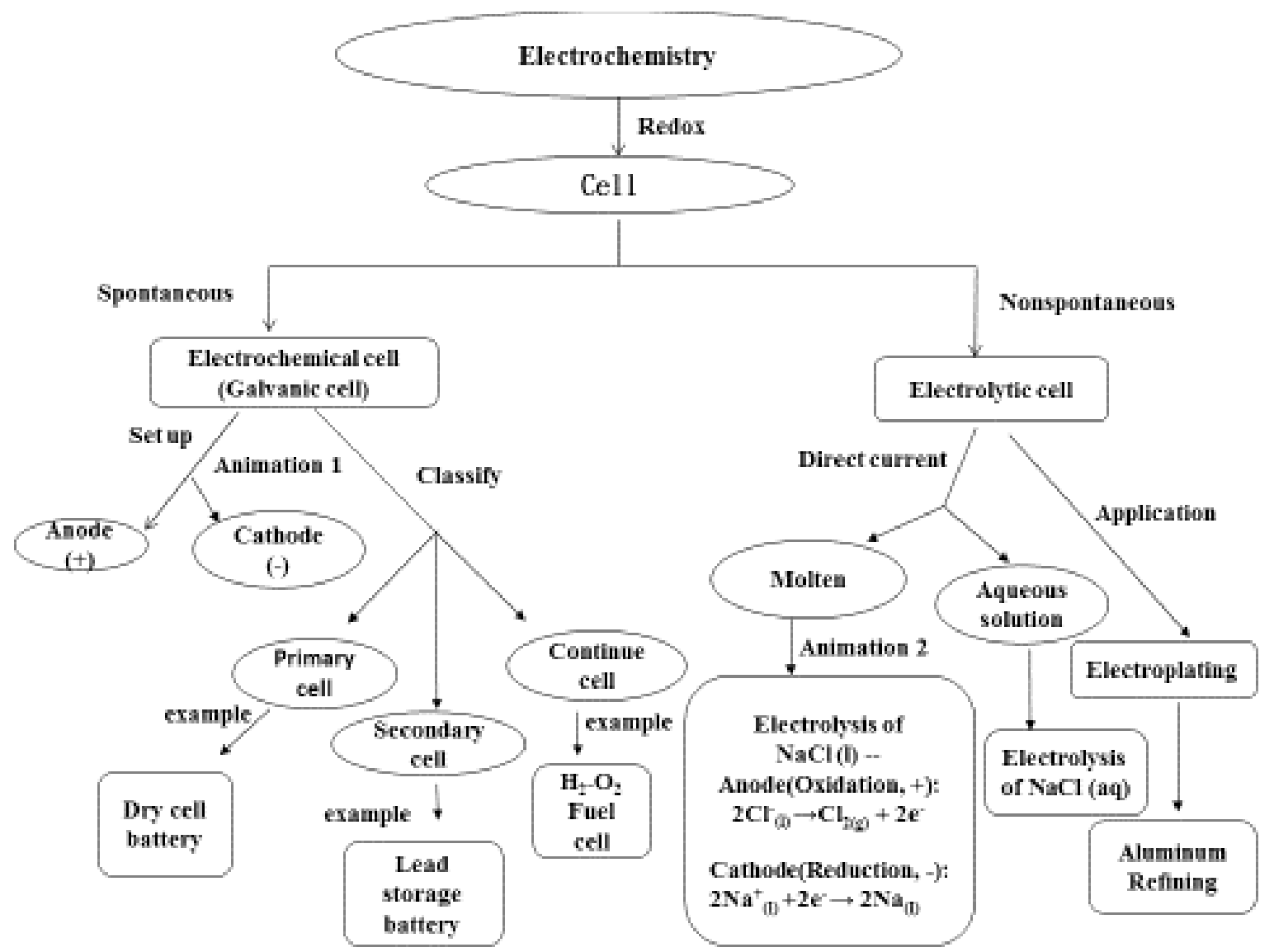

Figure 1. An indication of animated concept mapping in electrochemistry.

The computer-based animations in Figure 2(1) and Figure 2(2) give the ACM group a manipulating application to recognize the symbol-based reasoning. In Figure 2(1), the $\mathrm{U}$ tube of salt bridge contains a saturated $\mathrm{KCl}$ solution which provides an electrically conducting medium between $1 \mathrm{M} \mathrm{ZnSO}_{4}$ and $1 \mathrm{M} \mathrm{CuSO}_{4}$ solutions. The $\mathrm{U}$ tube openings are loosely plugged with cotton balls to prevent the $\mathrm{KCl}$ saturated solution from flowing into the containers while allowing the anions and cations to move across. Electrons flow externally from the Zinc anode to $\mathrm{Cu}$ cathode because of a difference in electric potential. These phenomena are presented in Galvanic cell animations which have been integrated in Figure 1 of ACM learning texts.

For the next stage in Figure 2(2), the electrolysis of $\mathrm{NaCl}_{(1)}$ is a nonspontaneous reaction in which two platinum electrodes are immersed in the molten sodium chloride and connected to a battery. The anode occurs into oxidation whose half reaction is $2 \mathrm{Cl}^{-} \rightarrow \mathrm{Cl}_{2(g)}+2 \mathrm{e}$. The cathode occurs into reduction whose half reaction was $\mathrm{Na}^{+}+\mathrm{e}^{-} \rightarrow \mathrm{Na}_{(1)}$. All phenomena are presented in electrolysis animations of molten sodium chloride which have been integrated into Figure 1.

There were positive interactions between students-students and instructors-students with ACM implemented concept mapping and three integrated animations. These were associated with different levels of students' conceptual understanding. Moreover, all three integrated animations, Galvanic cell, electrolysis and rust formation had remarkable influence on students' learning performances. The first being rule-based reasoning for the concept mapping and the second being symbol-based reasoning for two animations. It was an innovative intervention for the experimental group to clearly demonstrate their concept-based reasoning in electrochemistry. 
(1)

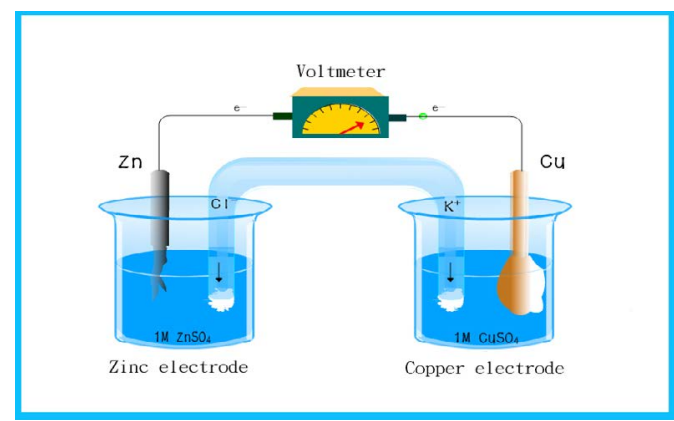

(2)

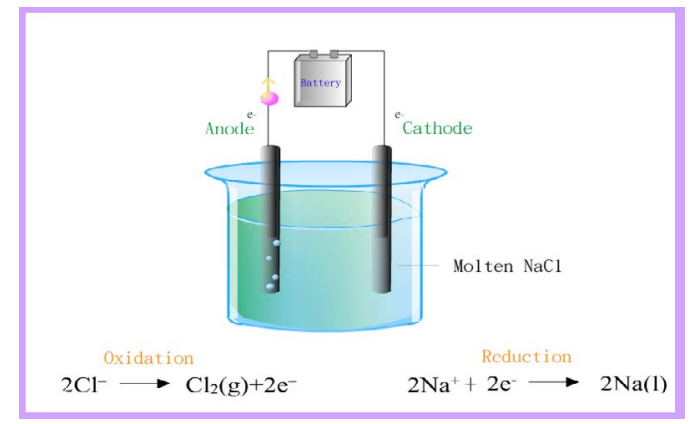

Figure 2. The two animations integrated into $\mathrm{ACM}$ in (1) Galvanic cell, and (2) Electrolysis of $\mathrm{NaCl}_{(1)}$.

All participants were given post-tests comprised of 12 test items (time limit 20 minutes) after the experimental teaching. Learning attitude questionnaire was administered only after ACM group's post-tests. Then a semi-structural questionnaire was proposed to elicit students' feedback to make up for a deficiency in the structural questionnaire. Finally, the students' retention achievement tests were held after four weeks.

\section{Data Analysis}

All students' responses to pre-tests, post-tests, retention-tests, and the final questionnaire were collected and classified with specific group codes. Students were scored in 12 achievement test items, with 8 points for correctly answering each test item, with 96 points for the total score. SPSS 22.0 Windows software was employed before and after the classes to gather statistical information. Descriptive statistics was carried out on two groups of students, and ANOVAs with significance levels set at 0.05 to test the main effects. In cases in which the $p$-values were less than or equal to 0.05 , Scheffe's post hoc comparisons were calculated within students' performances for further significant main effects of learning achievements and attitudes.

\section{Research Results}

The primary content design of students' four reasoning processes consists of two stages. The first stage provides a preliminary analysis and covariance, while the second stage describes students' learning feedback and ANOVAs. This study analyzes students' reasoning performances of ACM data models, such as achievement covariance, $t$-tests of pre-tests, post-test, retention-tests, and students' learning attitude of one-way ANOVA with three fundamental research results.

\section{Preliminary and Covariance Analyses}

In exploring students' learning achievements in model-based reasoning, and per Levene's error variances in authentic equality, it was confirmed that no significant differences $(p>.05)$ existed between the two groups, either in their homogeneity of independent variables or in that of the dependent variables. Since analyses of the two groups' covariate variables followed the homogeneity examinations of regression slope, the final results of achievement tests enabled students to accomplish their stratagem understanding of learning effects and responsive differences before and after instructions. Table 4 indicates descriptive statistics of the two groups' scores in the ACM and ST courses, learning achievements in pre-tests, post-tests, and retention-tests. Students' mean pretest scores were similar between the ST and the ACM groups, shown in Table 4. The pair-comparisons of Table 5 represent more elaborate covariant analyses 
Table 4. Descriptive statistical analyses of learning achievements for two groups'mean scores (M) and standard deviations (SD).

\begin{tabular}{cccccccc}
\hline & \multicolumn{2}{c}{ Pre-test } & \multicolumn{2}{c}{ Post-test } & \multicolumn{2}{c}{ Retention-test } \\
\hline Group & N & M & SD & M & SD & N & SD \\
\hline ST & 28 & 27.7 & 10.1 & 41.4 & 13.1 & 39.1 & 11.8 \\
ACM & 28 & 28.6 & 15.7 & 56.6 & 20.0 & 48.3 & 11.4 \\
Total & 56 & 28.1 & 13.1 & 49.0 & 18.4 & 43.7 & 12.4 \\
\hline
\end{tabular}

of significant learning differences between the ACM and ST groups. Examining the effective statistical figures of post-tests $(F=11.148, p<.01)$ for the two groups, the post-tests scores of ACM group outperformed those of the ST group. The students' significant analysis of retention-tests $(F=9.918, p<.01)$ also followed the same statistical results in that the learning achievements of the ACM group were superior to those of the ST group. Similarly, both the distributed score results of the post-tests and retention-tests confirmed the effectiveness of ACM instruction from the pair-comparisons of the two groups' statistical analyses. Also in Table 5, students' Cohen's effect sizes $f$ (0.461 and 0.636$)$ is higher in the two groups' post-tests and retention-tests (Cohen, 1988).

Furthermore, an independent sample t-test was employed to examine whether there existed any significant differences in post-tests and retention-tests for the pair-comparisons of the learning achievements of the experimental group. The final t-test of their learning difference $(t=3.362, p=.002)$ demonstrated that the scores of posttests were superior to those of the retention-tests in experimental groups' conceptually rule-based reasoning or symbol-based reasoning. Students' envisioning of ACM text with corresponding conceptual reasoning opened up the possibilities of strengthening authentic problem-solving performances with their continual active engagement of highly abstract and complex conceptual problems in electrochemistry.

Table 5. Summary of two groups of students' individual learning achievement of different ANOVAs in posttests and retention tests.

\begin{tabular}{cccccccc}
\hline Category & Source & SS & $d f$ & MS & F-ratio & $p$-value & $\mathbf{f}$ \\
\hline Post-test & Group & 3114.636 & 1 & 3114.636 & 11.148 & $.002^{* *}$ & .461 \\
& Error & 14807.557 & 53 & 279.388 & & & \\
Retention & Group & 1083.560 & 1 & 1083.560 & 9.918 & $.003^{* *}$ & .636 \\
test & Error & 5790.465 & 53 & 109.254 & & & \\
\hline
\end{tabular}

Note: ${ }^{* *} p<.01$

\section{Students' learning feedback and ANOVA}

This study highlighted the experimental group's strategic application in six subscales of learning attitude. The descriptive statistics of mean scores and standard deviation for their learning attitude of the six subscales were measured: $A_{1}$ (4.05 and 0.70), $A_{2}$ (3.92 and 0.67), $A_{3}$ (4.06 and 0.62), $A_{4}\left(4.06\right.$ and 0.68), $A_{5}(4.07$ and 0.70$)$, and $A_{6}$ (4.07 and 0.74) with the total mean score 4.04 and the standard deviation 0.69. The Cronbach's a values in the six subscales of learning attitude were $A_{1}(0.857), A_{2}(0.770), A_{3}(0.799), A_{4}(0.821), A_{5}(0.865)$, and $A_{6}(0.841)$. The overall Cronbach's a value of 0.948 for the total internal consistency in retest total scales which reached a satisfactory degree of dynamic statistic findings (Salta \& Tzougraki, 2004) and with a statistical mean score of $>3.50$ for all their learning attitudes (Su, 2008).

On account of ACM group's blocking variable, a series of ANOVAs were guided for the multi-variants of the Wilks' Lambda parameter upon attitude survey samples of the six subscales in Table 6 . Accordingly, Table 6 provides a brief summary of individual learning attitude with the F-ratios, p-values, effect sizes ( $f$ ), and Scheffé's post hoc comparisons. Students' dependent variables of the six learning attitudes are illustrated in Table 6 . It shows that 
ISSN 1648-3898 /Print/ ENHANGING STUDENTS' CORRESPINDING REASONING GF COGNITIVE PERFGRMANCES BY

positive dispositions in $A_{1}, A_{4}$ and $A_{6}$ were superior to neutral dispositions; and positive dispositions in $A_{1^{\prime}}, A_{2^{\prime}} A_{4^{\prime}} A_{5}$ and $A_{6}$ were superior to negative dispositions. The only dependent variable $A_{3}$ was estimated without significant differences in Table 6.

Table 6. Dispositions of individual ANOVAs learning attitudes in electrochemistry.

\begin{tabular}{|c|c|c|c|c|c|c|c|c|}
\hline \multirow{2}{*}{$\begin{array}{c}\text { Experimental } \\
\text { Course }\end{array}$} & \multirow{2}{*}{$\begin{array}{l}\text { Blocking } \\
\text { Variable }\end{array}$} & \multirow{2}{*}{$\begin{array}{l}\text { Analysis of } \\
\text { Variance }\end{array}$} & \multicolumn{3}{|c|}{ Attitude } & \multicolumn{3}{|c|}{ Measure } \\
\hline & & & $A_{1}$ & $A_{1}$ & $A_{1}$ & $A_{1}$ & $A_{1}$ & $A_{1}$ \\
\hline Electro- & Disposition & F-ratio & 5.129 & 4.452 & 2.701 & 5.699 & 4.076 & 6.893 \\
\hline \multirow[t]{6}{*}{ Chemistry } & toward & $p$-value & $.001^{* *}$ & $.002^{* *}$ & $.034^{*}$ & $.000^{* * *}$ & $.004^{* *}$ & $.000^{\star * *}$ \\
\hline & Chemistry & $f$ & .44 & .41 & .32 & .47 & .39 & .51 \\
\hline & (1.very positive, & Scheffé & $2>3$ & & & $2>3$ & $2>4$ & $2>3$ \\
\hline & 2. positive, & & $2>4$ & & & $2>4$ & & $2>4$ \\
\hline & 3. neutral, 4. negative, & & & & & & & \\
\hline & 5.very negative) & & & & & & & \\
\hline
\end{tabular}

Note: ${ }^{*} p<.05 ;{ }^{* *} p<.01 ;{ }^{* * *} p<.001$.

Based on Cohen's (1988) effect size ( $f$ ), the dominant index for different variables was evaluated in students' six learning attitudes of dispositions toward chemistry, with the effect sizes ranged between 0.32 and 0.51 , as shown in Table 6. There were several dependent variables $A_{1^{\prime}} A_{2^{\prime}} A_{4^{\prime}}$ and $A_{6}$ reaching above large effect sizes; and two dependent variables $A_{3}$ and $A_{5}$ indicated between medium and large effect sizes.

\section{Students'interviews}

For the subsequent interviews, three students were randomly selected from a high scoring group and a low scoring group on their post-tests. The interview consisted of the following three questions:

Question 1 -- Could ACM strategic applications in this study clarify students' detailed conceptions of electrochemistry, for example their conception of Galvanic cell, electrolysis and rust formation? The results indicated that four students' responses implied a fully developed feedback for both levels of higher score students (SH) and low score students (SL).

The $\mathrm{SH} 1$ response: All concept mappings linked the conceptions and guided me to construct well-designed drawings directly through Galvanic cell and electrolysis.

The SH2 response: Three colorful and interesting animations inspired my mind to capture how electrons, as an indicative symbol of myth, could transfer feasibly from microscopes to macroscopy in my understanding of electrochemistry.

The $S L 1$ response: Both attributes of abstract and complicated animations should be presented in a more simple and concise method to arouse my curiosity and interest in electrochemistry.

The SL3 response: With limited understanding, I could not comprehend the complicated rust formations from cathode to anode in integrated series of changeable animations.

Question 2 -- Did students discover more problem-solving accomplishments with ACM upgrading conceptions of Galvanic cell and electrolysis toward their decision-making manipulation of electrochemistry learning processes?

The SH3 response: With a favorable learning willingness, I could activate the concept mapping to renew ACM strategic problem-solving applications of Galvanic cell and electrolysis cell.

The SL2 response: Without adequate understanding, it was difficult for me to solve electrochemistry questions in relation to the concrete association of Galvanic cell and electrolysis cell. 
Question 3 -- Could students form more flexible opinions to integrate ACM applications derived from different perceptions toward their electrochemistry understanding?

The SH1 response: ACM strategic applications would facilitate my advanced conceptual learning with many advantages, such as attractive animated visions; motivate thinking texts, and creative new learning environment.

The SH2 response: To inspire my learning desire, ACM texts provided authentic conceptual guidance and comprehensive text program in electrochemistry understanding.

The SL3 response: I couldn't comprehend these abstract and complicated conceptions of Galvanic and electrolysis cell, with a short time span for electrochemistry learning.

Several initial cases of students' semi-structured questionnaire revealed different levels of successful models in their responses of cognitive reasoning for the interview questions listed above.

\section{Discussion}

By following the learning procedure of the ACM text, students could assume that their act of cognitive reasoning is centered upon their engagement of the following three supporting research subjects.

Supporting research subject 1, the first priority was to find participants' learning achievements in post-tests and retention-tests. The results indicated that the scores of the experimental group were superior to those of the control group, which were consistent with their conceptual understanding of concept mapping for rule-based reasoning (Weinerth et al., 2014; Yaman \& Ayas, 2015) and innovative animations knowledge for symbol-based reasoning (Su, 2008, 2017). The score comparison of two groups verified what had been reported by advanced studies of concept maps and/or animations (Adesope et al., 2013; Özmen, 2013) used in significant cognitive theory.

Supporting research subject 2, the overall data was to determine the separate scores of the experimental group's significant differences in post-tests and retention-tests. For students' complexity of learning achievements, their scores of post-tests were superior to those of retention-tests. The result showed that their retention score dropped by 8.28 , indicating that a students' corresponding loss of reasoning memory without continuous long term learning. Specifically, ACM strategic applications offered several advantages as researchers suggested (Redford, Thiede, Wiley, \& Griffin, 2012) when accompanied with abstract and complicated electrochemistry texts for students' problem-solving domains in reasoning process (Cheung, 2011; Sevian et al., 2015).

Supporting research subject 3 , the sequential responding implementation was to analyze students' feedback for structural and semi-structural questionnaires. It was reported that the higher score students with their adroitness of problem-solving reasoning could built up more hierarchical treatments of positive fulfillment of ACM learning to reduce their learning cognitive load as suggested by researchers (Huang, Chen, \& Ho, 2014; Sevian et al., 2015). Their dexterity for cognitive developments of positive feedback guided an effective problem-solving for ACM demonstration learning. This is in accordance with previous research which further demonstrates the benefits of ACM learning (Treagust, Chittleborough, \& Mamiala, 2003; Jaber \& BouJaoude, 2012).

To affirm students' engagements of ACM cognitive activities, all three supporting research subjects served as designate participants to develop their conceptual reasoning. Due to the limited problem-solving activities, the traditional assessment learning could not help most students to develop their conceptual understanding (Özmen, 2013; Su, 2017). To propose different instructional conditions, settings and experimental features, Adesope and Nesbit (2013) explicitly suggested that constructing concept mappings produced increasing knowledge transference for students' ACM achievement of cognitive activities. The findings within this research emphasized students' vital role with an innovative perspective of four corresponding reasoning processes for setting up problem-solving animations and concept mappings.

This research demonstrates more extended ACM advantages of problem-solving learning rather than the traditional static text. A distinction begins to arise for ACM learning and traditional text when the instructor employs appropriate ways of verifying more animated conceptions to conduct students' guidance of learning skills as comprehensive benefits indicated by Yang, Andre, Greenbowe, and Tibell (2003). For instance, students' participatory skills require deeper development of self-explanatory construction with ACM understanding. Concept mapping has been used as an individual medium in which learners store up their animated features to summarize or integrate abstract as well as complicated animations worked with an overall effect of mental conceptions. There is evidence for text designers, such as instructors, textbook authors, and researchers, to avoid students' anxiety 
and frustration while constructing students' ACM motivation to engage in the meaningful performance of four corresponding reasoning processes (Bahr \& Dansereau, 2001).

The goal of enhancing students' four corresponding reasoning processes assigned in two groups of students is functional cognitive developments for participants' self-construction and independent interactions. Students' participation has a collaborative reasoning performance in the four corresponding processes. At first, learners develop the initial model-based reasoning for static or dynamic visualizations to describe and explain the structure and properties of matter as stated by Erduran and Duschl (2004). Next to be followed by the propagative case-based reasoning, learners use their past experience to explain how to put their new conceptual reasoning into practice as the effective mental understanding in chemistry (Kovac, 2002). Unlike the first two corresponding processes, the third stage of rule-based reasoning facilitates learners to make quick predictions and problem-solving decisions in conjunction with the efficiency of cognitive learning and satisfactory feedback (Christian \& Talanquer, 2012). Most importantly, the fourth transferable stage of symbol-based reasoning will acquaint learners with their manipulation of chemical symbols for more recognized decision making in electrochemistry problem-solving (direct observations from Christian et al., 2012).

An analysis of the benefits of the four corresponding reasoning processes encourages participants to accumulate different learning perspectives and problem-solving performances. Any one of the four corresponding reasoning processes can be used sequentially to implement students' mediated cognition for the four reasoning processes from model-based reasoning to symbol-based reasoning. When students approach more complex reasoning processes with abstract chemical symbols, they may find it achievable to integrate the symbolic transposition of symbol-based reasoning conceptually for sophisticated electrochemistry knowledge. A close look at the present approach will explain students' problem-solving performances with the reassigned context of individual reasoning participation, which could not otherwise be acquired. The growing and cumulative correlations of the four reasoning processes make it fitting for students to enact their specific transpositions related to the supported finding in the conceptual constructions of problem-solving understanding (Jaber et al., 2012).

\section{Conclusions and Implications}

This research offered a favorable perspective towards measuring students'four cognitive reasoning processes as the successful participation of ACM problem-solving. It is important on the project that it offers a methodological departure from traditional scholarship on students' conceptual reasoning. They can do their decision-making accordingly by shifting the focus of analysis from other intervening skills of training factors to the model-based, case-based, rule-based and symbol-based reasoning processes. To a greater extent to fulfill students' self-directed and self-developed performances, a shift for an extending measurement of the ACM group's individual problemsolving explores the multivalent significances of the four reasoning processes. Furthermore, students' enthusiasm could be ignited in an ACM learning environment. These four reasoning processes complicate their problem-solving accommodation for a series of self-performances of electrochemistry knowledge.

In fact, after students' improvement in problem-solving performances, constantly shaped and received as they were, could be enhanced in the four corresponding reason processes recognized as their major cognitive power and ACM understanding levels. In this manner, this research makes a further contribution to students' acquisition of collaborative reasoning, as well as the mediator for all cognitive levels of electrochemistry development. Among a scarce source of limited research done in the four reasoning processes, there will be more discourses for students' coordination of individual conceptual growth related to animation-based visual activities. This is much needed in the future. It would also be the students' expectation for further research to develop creative and critical thinking by using essential learning skills in conjunction with technological development.

\section{Acknowledgements}

A short but sincere thank must also be given to the patronage of the Ministry of Science and Technology, MOST in Taiwan (under Grant No. MOST 103-2511-S-237-001 and MOST 105-2511-S-237-002-MY2). Without their help and financial support, this research could not have been completed in the present form. 


\section{References}

Adesope, O. O., \& Nesbit, J. C. (2013). Animated and static concept maps enhance learning from spoken narration. Learning and Instruction, 27, 1-10.

Akram, M., Johari, S., \& Ali, M. (2014). Conceptual difficulties of secondary school students in electrochemistry. Asian Social Science, 10 (19), 276-281.

Anderson, L. W., \& Krathwohl, D. R. (2001). A taxonomy for learning, teaching, and assessing. New York, NY: Longman.

Bahr, G. S., \& Dansereau, D. F. (2001). Bilingual knowledge maps (BiK-Maps) in second-language vocabulary learning. Journal of Experimental Education, 70, 5-24.

Cheung, D. (2011). Using diagnostic assessment to help teachers understand the chemistry of the lead-acid battery. Chemistry Education Research and Practice, 12, 228-237.

Chiou, C. C., Tien, L. C., \& Lee, L. T. (2015). Effects on learning of multimedia animation combined with multidimensional concept maps. Computers \& Education, 80, 211-223.

Christian, K., \& Talanquer, V. (2012). Modes of reasoning in self-initiated students groups in chemistry. Chemistry Education Research and Practice, 13 (3), 286-295.

Cohen, J. (1988). Statistical power analysis for the behavioral sciences (2nd Ed.). Hillsdale, NJ: Erlbaum.

David, S. B. (2003). High school biology: A group approach to concept mapping. The American Biology Teacher, 65 (3), $192-197$.

Erduran, S., \& Duschl, R. (2004). Interdisciplinary characterizations of models and the nature of chemical knowledge in the classroom. Student Science Education, 40, 105-138.

Gay, L. R. (1992). Educational research: Competencies for analysis and application (4th Ed.). New York: Macmillan Publish Company.

Holzinger, A., Kickmeier-Rust, M., \& Albert, D. (2008). Dynamic media in computer science education content complexity and learning performance: Is less more? Educational Technology \& Society, 11 (1), 279-290.

Huang, H. S., Chiou, C. C., Chiang, H. K., Lai, S. H., Huang, C. Y., \& Chou, Y. W. (2012). Effects of multidimensional concept maps on fourth graders' learning in web-based computer course. Computers \& Education, 58 (3), $863-873$.

Huang, K. L., Chen, K. H., \& Ho, C. H. (2014). Enhancing learning outcomes through new e-textbooks: A desirable combination of presentation methods and concept maps. Australasian Journal of Educational Technology, 30 (5), $600-618$.

Hwang, G. J., Wu, P. H., \& Ke, H. R. (2011). An interactive concept map approach to supporting mobile learning activities for natural science courses. Computers \& Education, 57, 2272-2280.

Jaber, L. Z., \& BouJaoude, S. (2012). A macro-micro-symbolic teaching to promote relational understanding of chemical reactions. International Journal of Science Education, 34 (7), 973-998.

Kao, G. Y. M., Lin, S. S. J., \& Sun, C. T. (2008). Breaking concept boundaries to enhance creative potential: Using integrated concept maps for conceptual self-awareness. Computers \& Education, 51(4), 1718-1728.

Kovac, J. (2002). Theoretical and practical reasoning in chemistry. Foundations of Chemistry, 4, $163-171$.

Kraft, A., Strickland, A. M., \& Bhattacharyya, G. (2010). Reasonable reasoning: Multi-variate problem-solving in organic chemistry. Chemistry Education Research and Practice, 11, 281-292.

Lin, L., \& Atkinson, R. K. (2011). Using animations and visual cueing to support learning of scientific concepts and processes. Computers \& Education, 56, 650-658.

Liu, T. C., Lin, Y. C., \& Tsai, C. C. (2009). Identifying senior high school students' misconceptions about statistical correlation and their possible causes: An exploratory study using concept mapping with interviews. International Journal of Science and Mathematics Education, 7, 791-820.

Nesbit, J. C., \& Adesope, O. O. (2006). Learning with concept and knowledge maps: A meta-analysis. Review of Educational Research, 76, 413-448.

Novak, J. D. (2010). Learning, creating, and using knowledge: Concept maps as facilitative tools in schools and corporations. New York, NY: Routledge.

Özmen, H. (2013). Effect of animation enhanced conceptual change texts on 6 th grade students' understanding of the particulate nature of matter and transformation during phase changes. Computers \& Education, 57, 1114-1126.

Redford, J. S., Thiede, K. W., Wiley, J., \& Griffin, T. D. (2012). Concept mapping improves meta-comprehension accuracy among 7 th graders. Learning and Instruction, 22, 262-270.

Salta, K., \& Tzougraki, C. (2004). Attitudes toward chemistry among 11 th grade students in high schools in Greece. Science Education, 88, 535-547.

Sevian, H., Bernholt, S., Szteinberg, G. A., Auguste, S., \& Pérez, L. C. (2015). Use of representations mapping to capture abstraction in problem solving in different courses in chemistry. Chemistry Education Research and Practice, 16, 429-446.

Simons, K. D., \& Klein, J. D. (2007). The impact of scaffolding and student achievement levels in a problem-based learning environment. Instruction Science, 35 (41), 41-72.

Soika, K., \& Reiska, P. (2014). Using concept mapping for assessment in science education. Journal of Baltic Science Education, $13(5), 662-673$.

Su, K. D. (2008). The effects of a chemistry course with integrated information communication technologies on university students' learning and attitudes. International Journal of Science and Mathematics Education, 6, 225-249. 
Su, K. D. (2016). Strengthening strategic applications of problem-solving skills for Taiwan students' chemistry understanding. Journal of Baltic Science Education, 15 (6), 662-679.

Su, K. D. (2017). Tactic fulfillments of three correlations for problem-solving maps and animated presentations to assess students' stoichiometry performances. Journal of Baltic Science Education, 16 (5), 733-745.

Taber, K. S. (2014). Ethical considerations of chemistry education research involving 'human subjects.' Chemistry Education Research and Practice, 15, 109-113.

Te'eni, D., Carey, J., \& Zhang, P. (2007). Human computer interaction: Developing effective organizational information systems. New York: John Wiley \& Sons.

Treagust, G., Chittleborough, G., \& Mamiala, T. (2003). The role of submicroscopic and symbolic representations in chemical explanations. International Journal of Science Education, 25 (11), 1353-1368.

Weinerth, K., Koenig, V., Brunner, M., \& Martin, R. (2014). Concept maps: a useful and usable tool for computer-based knowledge assessment? A literature review with a focus on usability. Computers \& Education, 78, 201-209.

Yaman, F., \& Ayas, A. (2015). Assessing changes in high school students' conceptual understanding through concept maps before and after the computer-based predict-observe-explain (CB-POE) tasks on acid-base chemistry at the secondary level. Chemistry Education Research and Practice, 16, 843-855.

Yang, E. M., Andre, T., Greenbowe, T. J., \& Tibell, L. (2003). Spatial ability and the impact of visualization/animation on learning electrochemistry. International Journal of Science Education, 25 (3), 329-349.

Received: April 08, 2018

Accepted: July 19, 2018

King-Dow Su

Chemistry Ph. Dr., Professor, Department of Hospitality Management and Center for General Education, Hungkuo Delin University of Technology, No.1, Lane 380, Ching-Yun Road, Tu-Cheng District., New Taipei City, Taiwan 23646, R.O.C. \& Center for General Education, Chung Yuan Christian University, 200 Chung Pei Road, Chung Li District, Taoyuan City, Taiwan 32023, R.O.C.

E-mail: su-87168@mail.hdut.edu.tw 